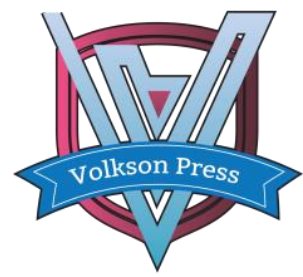

Contents List available at VOLKSON PRESS

Economics \& Management Innovations(EMI)

DOI : http://doi.org/10.26480/icemi.01.2017.15.17

\title{
Influence of Ethical Climate on Task-focused Helping Behavior
}

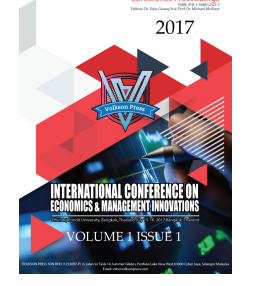

\author{
Shuang Chen ${ }^{1,2}$, Jing Chen ${ }^{2}$, and LijiaHu ${ }^{1}{ }^{*}$ \\ 1 Management School, Shao Guan University, Shao Guan, Guang Dong China \\ 2 Business School, Macau University of Science and Technology, Macau, China \\ *E-mail: hulijia2003@163.com
}

This is an open access article distributed under the Creative Commons Attribution License, which permits unrestricted use, distribution, and reproduction in any medium, provided the original work is properly cited.

\section{ARTICLE DETAILS}

\section{Article History:}

Received 02 october 2017

Accepted 06 october 2017

Available online 11 october 2017

\section{Keywords:}

ethical climate; other-focused moral reasoning; self-focused moral reasoning; task- focused interpersonal helping behavior; inter-personal citizenship behavior (ICB).

\section{ABSTRACT}

Structural equation analysis with AMOS software utilized to examine the relationships between two-dimension ethical climate and task-focused interpersonal helping behavior. The result shows that a) other-focused moral reasoning ethical climate (OEC) is an important predictor of employees' task-focused interpersonal helping behavior, and b) self-focused moral reasoningethical climate (SEC) alone is not related with task-focused helping behavior, however, c) when accompany with OEC, SEC become significantly and positively related with taskfocused helping behavior. This finding indicates that OEC plays a very curial role, it works like a kind of catalyzer or guarantee, which not only positive effect the helping behavior by itself, but also can turn SEC positive effect helping behavior.

\section{Introduction}

Nowadays, there was an increased awareness of the importance of business ethics, and ethical climate has become an increasingly hot topic around the world [1]. Scholars emphasize the importance of studying ethical climate, and try to get a better understand of those issues. Existing researches stated that ethical climate is a type of organizational work climate [2], it affecting employees' attitudes and behaviors, and organizational outcomes [3].

Meanwhile helping behavior in workplace is critical to the functioning of many organizations. Experimental evidence also shows that citizenship benefits not only individuals performing the behavior (e.g., increased performance evaluations) but organizations as well (e.g., productivity, efficiency, reduced costs, customer satisfaction, and reduced turnover) [4]. In addition, evidence demonstrating job performance consists of both task and citizenship behaviors, require behaviors that are task focused as well as those that are social, cooperative, and helpful in nature [5].

The present study will examine relationships of two-dimension ethical climate (self-focused moral reasoning, and other-focused moral reasoning, hereinafter referred to as SEC and OEC) to task- focused interpersonal helping behavior.

\section{Theory and Hypotheses}

\section{$2.1 \quad$ Two-Dimension Ethical Climate}

First formulated and proposed byVictor and Cullen $(1987,1988)$, ethical climate was conceptualized as a multidimensional construct, and represents a sub-climate of the organizational climate. The original construct of Victor and Cullen (1987, 1988)'s ethical climate contains nine theoretical climate types. However, in empirical studies, different clusters of the nine theoretical climate types have emerged across studies [6]. In addition, Arnaud and Schminke [6] argued that research shows few individuals ever reach the post-conventional level of moral reasoning, and thus, shared climate perceptions are unlikely to develop at universalistic criteria. Instead, shared perceptions are likely to develop at the self-focused (pre-conventional) and other-focused (conventional) levels at which the most individuals engage in moral reasoning.

Therefore, Arnaud (2012) conceptualize two dimensions on reasoning component of ethical climate: self-focused and other-focused moral reasoning.

Based on egoism, self-focused moral reasoning ethical climate (SEC) refers to employees in the department are primary concerned with selfinterest, always think of their own welfare when faced with a difficult decision. It refer to individuals making decisions based on their own interest.

Other-focused moral reasoning ethical climate (OEC) is closed to benevolence and careing climates which decisions and actions are taken to produce the greatest good for the greatest number of people. Including three levels: consideration peers' welfare in the department, the whole interests of the department, the right and sense of responsibility for society and humanity.

In a summary, the assumption of present study is that every employee may has his or her own specific perception of ethical climate towards their organization, these perceptions can be classified in two general categories (i.e. SEC and OEC), SEC will rise when individual, for example, feel a high work pressure, lack of communication between colleagues, lack of trusts, etc.; OEC will be high when employee feel everyone is caring about others, for example, employees experience more trust toward their colleagues and organization, feel a sense of security, etc.

2.2 Two-Dimension Ethical Climate and task-focused interpersonal helping behavior

Research reports that the presence of ethical climate can enhance employees' attitudes toward their work and their organizations. Following Mischel's observation, hundreds of studies have investigated the relationships between various situational factors and spontaneous helping behavior in short-term exchanges [7]. Fischer [8] stated that many situational factors have been found to affect helping behavior, including number of bystanders present, the ambiguity of the helping situation, mood, perceived deviance of the person needing help, 
temperature, and noise. Taken these studies together, it can come to a conclusion that the situational factors have some impaction on helping behavior. Organization's ethical climates (such as a reward climate and a service climate) are important to organizations, because it is linked to the ethical behavior of employees [9]. Helping behavior as an ethical behavior influences by ethical climate within the organization [3].

An extensive literature on helping addresses the question of why an individual might help other individual. In fact, Flynn and Lake [10] argued that this question is the primary focus of the helping literature. Grant and Dutton [11] stated that work environments characterized by a need for collaboration and coordination will feature pervasive helping. In these environments, helping behavior might be widespread and consist of more than a simple exchange.

Employees under other-focused moral reasoning work climate and selffocused moral reasoning may vary in their decision-making process and hold different attitudes towards others. Employees are expected to work together and help others under a cooperative situation in the work-place [12]. If the employees under other-focused ethical climate (e.g., employee feel people around are more caring about others). When the employees feel they have received good treatment from a servant leader or their coworkers, they will have motivation to reciprocate the favorable treatment and contribute to the organization beyond the inrole duty [13], employees may feel more pressure to behave unethically, and more likely to help each other.

However, when team members encountered conflicts and disagreement in the work domain, often develop self-focused ethical climate. For instance, Grant and Patil [14] argued that norms of self- interest inhibit helping. Kim, O'Neill [15] stated that the higher the level of envy of employees, the less employees are willing to offer voluntary helping behavior to coworkers. In sum, employee under a self-focused moral reasoning ethical climate, in which all employees only care about their selves and put self interest in front of other employees, will less willing to help their coworkers.

Ethical climate involves the perceptions of other-focused moral reasoning and self-focused moral reasoning work environment in the organization [6], and the two type of ethical environment may predict the helping behavior occur within the company. Other-focused ethical climate should encourage more ethical behaviors while self-focused ethical climate should be associated with less ethical behaviors. Therefore, this study is going to examine how self-focused and otherfocused moral reasoning work climate related employee's helping behavior. The assumptions are as below: Hypothesis 1: OEC is positively related to task-focused helping behavior.

Hypothesis 2: SEC is negatively related to task-focused helping behavior.

\section{Method}

\subsection{Participants and procedure}

Data were obtained from 463 full-time employees from different organizations in China. The occupations of the participants including manager, technician, salesman, clerk, accountant, custom service, teacher, and so on. The participants were invited to complete a webbased survey by using their own cellphones or PCs, and received a $¥ 5$ gift. $48.2 \%$ of the participants were men, $51.8 \%$ female; $43.8 \%$ participants with the age between 26 and $30,83.6 \%$ under 35 years old; $26.8 \%$ tenure

of participants were between 1 and 3 years, $26.6 \%$ between 3 and 5 years, $74.7 \%$ under 5 years.

\subsection{Measures}

Ethical climate. We adopted Arnaud and Schminke [6]'s ECQ twodimension ethical climate. The scale consists of 10 items, using a fivepoint Likert scale ( 1 = never, $5=$ always) and sample item of SEC: "People around here are mostly out for themselves" $(\alpha=0.89)$; "People in my department are actively concerned about their peers' interests" ( $\alpha=$ 0.80 ) for OEC. Thus, a low score shows the absence of a climate, and a high score shows the presence of a climate. In addition, we conducted a CFA for the scale of two-dimension ethical climate. Here, the two-factor model showed a better fit indexes $\left(\chi^{2}[32.00]=79.47, \mathrm{CFI}=0.98, \mathrm{IFI}=0.98\right.$, RMSEA $=0.06)$ than the one-factor model $\left(\chi^{2}[32.00]\right.$

$=328.77, \mathrm{CFI}=0.85, \mathrm{IFI}=0.85, \mathrm{RMSEA}=0.14)$. The results indicate that the scales do possess adequate discriminant and convergent validity for use in hypotheses testing.
The measuring items of helping behavior were selected from the two complementary forms of inter- personal citizenship behavior (ICB), taskfocused ICB [16]. We use task-focused ICB items to measuring taskfocused helping behavior occurs within the work please. A sample item: "Helps coworkers with work when they have been absent." $(\alpha=.90)$. Rated on a 7-point scale

\section{Result}

\subsection{Descriptive Statistics}

Table 1 shows the means, standard deviations, inter-correlations, and internal consistencies of the study variables.

Table 1 Means, standard deviations, inter-correlations, and Conbrach's $\alpha$

\begin{tabular}{|c|c|c|c|c|c|c|c|c|c|c|}
\hline & & Mean & S. D. & 1 & 2 & 3 & 4 & 5 & 6 & 7 \\
\hline 1. SEX & & 1.52 & 0.50 & -- & & & & & & \\
\hline $\begin{array}{l}\text { 2. } \mathrm{AGE} \\
\text { 3. } \mathrm{EDU}\end{array}$ & & 3.41 & 1.28 & -.08 & - & & & & & \\
\hline 4. Tenure & & 4.38 & 1.13 & .01 & $-.14^{* *}$ & - & & & & \\
\hline $\begin{array}{l}5 . \mathrm{SEC} \\
6 . \mathrm{OEC}\end{array}$ & & 2.72 & 1.38 & -.03 & $.65^{* * *}$ & -.09 & - & & & \\
\hline \multirow{2}{*}{ 6. OEC } & & 2.83 & 0.98 & -.08 & .03 & $-.14^{* *}$ & .09 & (.89) & & \\
\hline & & 3.37 & 0.80 & .01 & .03 & -.08 .0 & .00 & $-.18^{* *}$ & (.80) & \\
\hline 7. Helping Behavior & 4.62 & 1.09 & .03 & -.01 & & 4 & .00 & .03 & $.42^{* * *}$ & (.90) \\
\hline
\end{tabular}

Notes: $\mathrm{n}=463$ employees, EUD=education, $\mathrm{SEC}=$ self-focused moral reasoning ethical climate, $\mathrm{OEC}=$ other-focused moral reasoning ethical climate, ${ }^{*} \mathrm{p}<0.05$, ** $\mathrm{p}<0.01$; the alpha internal-consistency reliability coefficients appear in parentheses along the main diagonal.

\subsection{Hypotheses Testing}

First, we conducted confirmatory factor analysis to test the three-factor measurement model, the result provided a good fit to the data $\left(\chi^{2}[286.00]=\right.$ 524.01, $\mathrm{CFI}=0.96, \mathrm{IFI}=0.96, \mathrm{RMSEA}=0.046$ ). And all the competitive models did not showed a better fit. Then we utilize AMOS software to build the SEM model and test the direct effects of ethical climate to task-focused interpersonal helping behavior (hypotheses 1and 2). The result shows that the structure model had a good fit $\left(\chi^{2}[98.00]=192.36, \mathrm{CFI}=0.97\right.$, IFI $=0.97$, and RMSEA $=0.046$ ) (see figure 1). The results demonstrated that perceived OEC and SEC were both positively associated with helping behavior $(\beta=.53$ for OEC to helping behavior, $\mathrm{p}<.001$; and $\beta=.15$ for SEC to helping behavior, $\mathrm{p}$ $<.01$ ). Results supported Hypotheses 1 . However, although the relationship of SEC to helping behavior was significant, the result was just opposite to our expectations that SEC and helping behavior were negatively related, so Hypotheses 2 was not supported.

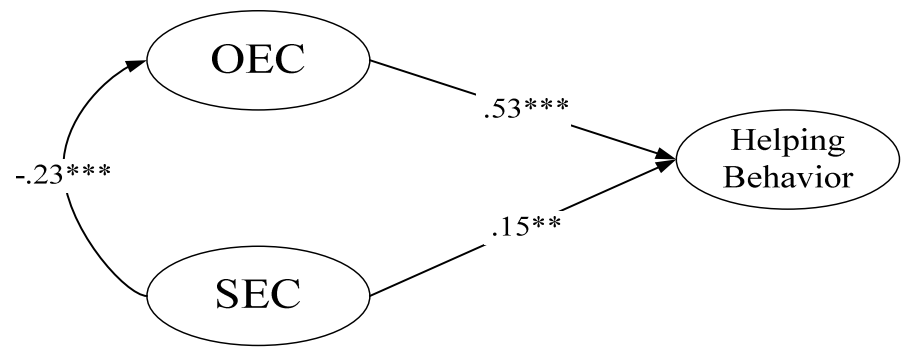

Notes: $n=463$ employees, OEC $=$ other-focused moral reasoning ethical climate, $\mathrm{SEC}=$ self-focused moral reasoning ethical climate, $* \mathrm{p}<0.05, * * \mathrm{p}$ $<0.01$;

Figure 1. The result of the structural model

\section{Conclusion}

\subsection{Discussion and Implications}

According the result of our study, we can learn that, first, OEC is significantly positive related with the task-focused helping behavior. Second, instead negatively influence helping behavior, SEC by itself is not related with task-focused helping behavior, on the contrary, it may contribute to task-focused IHB accompany with OEC. That means managers need not to worry about that SEC will negative influence task-focused helping behavior among employees. Instead managers who emphasize the importance of high level of helping in the company, should pay more attention to employees' perceived OEC of the organization, for OEC is not only an important predictor of employees' helping behavior, which will also work like a security or assurance, and turn SEC significantly 
improve work related helping behavior. In other words, SEC is not always the least wanted climate in organizations, managers may consider SEC as a potential contributor towards task-focused helping behavior.

\subsection{Limitations and Future Research}

First, applicability of dichotomy ethical climate need further validation. Another limitation of the current study is that all data were self-reported and collected from respondents at two time points. This may have given rise to common method bias.

Future research should adopt a longitudinal study design and assess these variables from multiple sources and at multiple time points to better understand the relationships among them. Interestingly, we need a better understanding the two-dimension ethical climate and its underlying influence mechanisms. Researchers may also bring other potential relevant variables in the model (e.g., work resources, personfocused ICB) to enrich the present research.

\section{References}

[1] Yener, M., M. Yaldıran, and S. Ergun, The Effect of Ethical Climate on Work Engagement. Procedia - Social and Behavioral Sciences, Vol.58 (2012), p. 724-733.

[2] Martin, K.D. and J.B. Cullen, Continuities and extensions of ethical climate theory: A meta-analytic review. Journal of Business Ethics, Vol.69, No.2 (2006), p. 175-194.

[3] Wimbush, J.C. and J.M. Shepard, Toward an understanding of ethical climate: Its relationship to ethical behavior and supervisory influence. Journal of Business Ethics, Vol.13, No. 8 (1994), p.637- 637-

[4] Podsakoff, N.P., et al., Individual-and organizational-level consequences of organizational citizenship behaviors: A meta-analysis. Journal of Applied Psychology, Vol.94, No.1 (2009), p. 122.

[5] Ellington, J.K., E.C. Dierdorff, and R.S. Rubin, Decelerating the diminishing returns of citizenship on task performance: The role of social context and interpersonal skill. Journal of Applied Psychology, Vol. 99, No.4 (2014), p. 748-758.

[6] Arnaud, A. and M. Schminke, The Ethical Climate and Context of Organizations: A Comprehensive Model. Organization Science, Vol.23, No.6 (2012), p. 1767-1780.
[7] Lefevor, G.T. and B.J. Fowers, Traits, situational factors, and their interactions as explanations of helping behavior. Personality and Individual Differences, Vol.92 (2016), p. 159-163.

[8] Fischer, P., et al., The bystander-effect: a meta-analytic review on bystander intervention in dangerous and non-dangerous emergencies. Psychological bulletin, Vol.137, No.4 (2011), p. 517.

[9] Treviño, L.K., K.D. Butterfield, and D.L. McCabe, The ethical context in organizations: Influences on employee attitudes and behaviors. Business Ethics Quarterly, Vol.8 , No.3 (1998),p. 447-47

[10] Flynn, F.J. and V.K. Lake, If you need help, just ask: underestimating compliance with direct requests for help. Journal of personality and social psychology, Vol.95, No.1 (2008), p. 128.

[11] Grant, A. and J. Dutton, Beneficiary or benefactor are people more prosocial when they reflect on receiving or giving? Psychological science, Vol.23, No.9 (2012), p. 1033-1039.

[12] 12] West, M., K.G ith, and D. Tjosvold, Past, present, and future perspectives on organizational cooperation. International Handbook of Organizational Teamwork and Cooperative Working,(2003), p. 575-597.

[13] Van Dyne, L., D. Kamdar, and J. Joireman, In-role perceptions buffer the negative impact of low LMX on helping and enhance the positive impact of high LMX on voice. Journal of Applied Psychology, Vol. 93, No.6 (2008), p. 1195.

[14] Grant, A.M. and S.V. Patil, Challenging The Norm of SelfInterest: Minority Influence and Transitions to Helping Norms in Work Units. Academy of Management Review, Vol.37, No.4 (2012), p. 547-568.

[15] $15 \mathrm{~m}$, S., J.W. O'Neill, and H.-M. Cho, When does an employee not help coworkers? The effect of leader-member exchange on employee envy and organizational citizenship behavior. International Journal of Hospitality Management, Vol.29, No.3 (2010), p. 530-537.

[16] Settoon, R.P. and K.W. Mossholder, Relationship quality and relationship context as antecedents of person- and task-focused interpersonal citizenship behavior. Journal of Applied Psychology, Vol.87, No.2 (2002), p. 255-267. 